\title{
Refining a zoogeographic puzzle: Mitochondrial diversity in the clinging jellyfish Gonionemus and its implications for understanding the origins of clinging jellyfish in the Northwest Atlantic Ocean
}

\author{
Annette F Govindarajan ${ }^{\text {Corresp., }}{ }^{1}$ ， Mary R Carman ${ }^{1}$ ， Marat R Khaidarov ${ }^{2,3}$ ， Alexander Semenchenko ${ }^{3}$, John $\mathbf{P}$ \\ Wares ${ }^{4,5}$ \\ 1 Biology Department, Woods Hole Oceanographic Institution, Woods Hole, United States \\ 2 A.V. Zhirmunsky Institute of Marine Biology, National Scientific Center of Marine Biology Far Eastern Branch, Russian Academy of Sciences, Vladivostok, \\ Russia \\ 3 Far Eastern Federal University, Vladivostok, Russia \\ 4 Department of Genetics, University of Georgia, Athens, United States \\ 5 Odum School of Ecology, University of Georgia, Athens, United States \\ Corresponding Author: Annette F Govindarajan \\ Email address: afrese@whoi.edu
}

Determining whether a population is introduced or native to a region can be challenging due to inadequate taxonomy, the presence of cryptic lineages, and poor historical documentation. For taxa with resting stages that bloom episodically, determining origin can be especially challenging as an environmentally-triggered abrupt appearance of the taxa may be confused with an anthropogenic introduction. Here, we assess diversity in mitochondrial cytochrome oxidase I sequences obtained from multiple Atlantic and Pacific locations, and discuss the implications of our findings for understanding the origin of clinging jellyfish Gonionemus in the Northwest Atlantic. Clinging jellyfish are known for clinging to seagrasses and seaweeds, and have complex life cycles that include a resting stage. They are especially notorious as some, although not all, populations are associated with severe sting reactions. The worldwide distribution of Gonionemus has been aptly called a "zoogeographic puzzle" and our results refine, rather than resolve the puzzle. We find a relatively deep divergence that may indicate cryptic speciation between Gonionemus from the Northeast Pacific and Northwest Pacific/Northwest Atlantic. Within the Northwest Pacific/Northwest Atlantic clade, we find haplotypes unique to each region. We also find one haplotype that is shared between highly toxic Vladivostok-area populations and some Northwest Atlantic populations. Our results are consistent with multiple scenarios that involve both native and anthropogenic processes. We evaluate each scenario and discuss critical directions for future research, including improving the resolution of population genetic structure, identifying possible lineage admixture, and better characterizing and quantifying the toxicity phenotype. 
1

2

3

4

5 Annette F. Govindarajan ${ }^{1}$, Mary R. Carman ${ }^{1}$, Marat R. Khaidarov²,3, Alexander A.

6 Semenchenko 3 , John P. Wares ${ }^{4,5}$

7

$8{ }^{1}$ Biology Department, Woods Hole Oceanographic Institution, Woods Hole, MA, USA

$9 \quad{ }^{2}$ A.V. Zhirmunsky Institute of Marine Biology, National Scientific Center of Marine Biology

10 Far Eastern Branch, Russian Academy of Sciences, Vladivostok, Russia

$11 \quad{ }^{3}$ Far Eastern Federal University, Vladivostok, Russia

$12{ }^{4}$ Department of Genetics, University of Georgia, Athens, Georgia, USA

13 Odum School of Ecology, University of Georgia, Athens, Georgia, USA

17 Corresponding Author: Annette F. Govindarajan, afrese@whoi.edu 


\section{Abstract}

22 Determining whether a population is introduced or native to a region can be challenging due to

23 inadequate taxonomy, the presence of cryptic lineages, and poor historical documentation. For

24 taxa with resting stages that bloom episodically, determining origin can be especially challenging

25 as an environmentally-triggered abrupt appearance of the taxa may be confused with an

26 anthropogenic introduction. Here, we assess diversity in mitochondrial cytochrome oxidase I

27 sequences obtained from multiple Atlantic and Pacific locations, and discuss the implications of

28 our findings for understanding the the origin of the clinging jellyfish Gonionemus in the

29 Northwest Atlantic. Clinging jellyfish are known for clinging to seagrasses and seaweeds, and

30 have complex life cycles that include a resting stage. They are especially notorious as some,

31 although not all, populations are associated with severe sting reactions. The worldwide

32 distribution of Gonionemus has been aptly called a "zoogeographic puzzle" and our results

33 refine, rather than resolve the puzzle. We find a relatively deep divergence that may indicate

34 cryptic speciation between Gonionemus from the Northeast Pacific and Northwest

35 Pacific/Northwest Atlantic. Within the Northwest Pacific/Northwest Atlantic clade, we find

36 haplotypes unique to each region. We also find one haplotype that is shared between highly toxic

37 Vladivostok-area populations and some Northwest Atlantic populations. Our results are

38 consistent with multiple scenarios that involve both native and anthropogenic processes. We

39 evaluate each scenario and discuss critical directions for future research, including improving the

40 resolution of population genetic structure, identifying possible lineage admixture, and better

41 characterizing and quantifying the toxicity phenotype. 


\section{Introduction}

45 Invasive species can have harmful impacts on native taxa and disrupt ecosystem functioning 46 (Molnar et al., 2008; Gallardo et al., 2016) and in some cases have direct negative impacts on

47 human health (Ruiz et al., 1997; Pyšek \& Richardson, 2010). Reconstructing invasion histories is 48 important for illuminating anthropogenic dispersal pathways and management (Molnar et al., 49 2008). However, determining if and when species invasions have occurred is challenging for 50 several reasons: the invasion may have occurred decades or more in the past, local taxonomic 51 baseline data may be lacking, and the invaders may be morphologically similar to local 52 organisms (Carlton, 2009). Compounding these difficulties, there may be multiple inputs of 53 invaders, sometimes originating from different source regions (Geller et al., 1997;

54 Simon-Bouhet, Garcia-Meunier \& Viard 2006; Roman 2006). Accordingly, many species are 55 considered cryptogenic and cannot be classified as introduced or native with confidence 56 (Carlton, 1996). In some instances, organisms may exhibit different phenotypes in their introduced range than in their native range (Miglietta \& Lessios, 2009; Krueger-Hadfield, 2016), making morphology-based identifications difficult. Molecular approaches can be very useful in identifying non-native taxa (Geller, Darling \& Carlton, 2010), but results are also not always clear-cut. Sufficient sampling in both the source and invasive ranges is crucial to accurately

61 resolve invasion histories and dispersal pathways (e.g., Darling et al., 2008, Yund, Collins \& 62 Johnson, 2015).

63 The hydrozoan Gonionemus vertens (A. Agassiz in L. Agassiz 1862) is native to the 64 Pacific and thought to be introduced in Europe (Edwards, 1976; Bakker et al., 1980), eastern 65 North America (reviewed in Govindarajan \& Carman, 2016), and South America (Rodriguez et 66 al., 2014). Its worldwide distribution has been called a "zoogeographic puzzle" due to its 
67 episodic and disjunct populations (Tambs-Lyche, 1964). In the Northwest Atlantic, G. vertens

68 was first recorded in 1894 in Woods Hole, MA and nearby locations. Medusae typically cling to

69 eelgrass and macroalgae in sheltered shallow water bays and coves. G. vertens life cycle includes

70 cryptic polyp and cyst stages (Perkins, 1902; Uchida, 1976) which could facilitate its

71 unintentional dispersal to new areas. In Woods Hole, medusae abruptly disappeared circa 1930

72 when the eelgrass, its preferred substrate, was decimated due to a wasting disease (Bakker,

73 1980). However at least one small population persisted on the nearby island of Martha's

74 Vineyard (approximately $8 \mathrm{~km}$ south of Woods Hole) (Govindarajan \& Carman, 2016). As well,

75 there were sporadic medusae sightings over several decades in the Gulf of Maine (Govindarajan

76 \& Carman, 2016). Beginning in 1990, G. vertens appeared to experience a regional resurgence,

77 with regular new observations near and beyond the Woods Hole region in the Northwest Atlantic

78 (Govindarajan \& Carman, 2016).

G. vertens is notorious for causing severe stings in the Northwest Pacific in the Sea of

80 Japan (Pigulevsky \& Michaeloff, 1969; Yakovlev \& Vaskovsky, 1993). Symptoms vary between

81 victims, but may include extreme pain, respiratory distress, paralysis, hallucinations, and

82 blindness, which can last 3 to 5 days. G. vertens in the eastern Pacific and until recently, in its

83 invasive ranges, has not been reported to cause sting reactions in humans (Naumov, 1960).

84 However, since 1990, some Northwest Atlantic populations appear to cause stings similar to

85 those reported from the western Pacific (Govindarajan \& Carman, 2016). These observations,

86 coupled with regular new sightings, suggest that a second wave of $G$. vertens invaders,

87 originating from the western Pacific, could be present in the Northwest Atlantic (Govindarajan \&

88 Carman, 2016). 
90 2009). G. vertens was originally thought to comprise two varieties, $G$. vertens vertens and $G$.

91 vertens murbachii Mayer 1901 (Naumov, 1960). G. vertens vertens, with a "hemisphaerical or

92 somewhat flattened" umbrella and faint yellow-green coloration, was described from the eastern

93 and western North Pacific, including in the Sea of Japan, the Aleutians Islands, and Puget Sound.

94 G. vertens murbachii, with a completely transparent umbrella and numerous tentacles, was

95 thought to occur in the Atlantic coasts of Europe and North America and the Mediterranean

96 (Naumov, 1960). Russell (1953) suggested that G. murbachii may be characterized by a flatter

97 bell than $G$. vertens. Dangerous stings were recorded from a subset of western Pacific G. vertens

98 vertens only (Naumov, 1960). Later thinking viewed the Atlantic forms as stemming from the

99 Pacific via human-mediated transport (Tambs-Lyche, 1964; Edwards, 1976; Bakker, 1980;

100 Govindarajan \& Carman, 2016). Because the initial Atlantic forms did not cause painful stings, it

101 was thought that they originated from the less toxic northeastern Pacific populations. Historical

102 northwest Atlantic G. vertens were believed to have arrived either directly from the northeastern

103 Pacific, or indirectly by way of Europe (Edwards, 1976), while contemporary G. vertens is

104 hypothesized to have arrived from a northwestern Pacific source (Govindarajan \& Carman, 105 2016).

106 Our goal is to determine the origin of contemporary Northwest Atlantic (NWA)

107 Gonionemus populations. We will test the hypothesis that contemporary NWA populations

108 derive some diversity from Northwest Pacific (NWP) populations. To better constrain possible

109 sources, we will also assess population divergence between Northwest Pacific (NWP) and

110 Northeast Pacific (NEP) populations. We evaluate 182 mitochondrial cytochrome oxidase I

111 (COI) sequences from Gonionemus obtained from 12 North Atlantic and potential source 
112 populations in the North Pacific. Our sampling includes NWA sites where Gonionemus has not

113 previously been recorded. It also includes NWP sites that harbor highly toxic populations in the

114 Peter the Great Gulf near Vladivostok, Russia.

\section{5}

\section{Methods}

\section{Sample collection}

118 Atlantic and Pacific medusae were collected by snorkeling or by net from boats or floating

119 docks, or from colleagues (Table 1). We refer to locations in the Northwest Atlantic as NWA,

120 Northeast Atlantic as NEA, Northwest Pacific as NWP, and Northeast Pacific as NEP. Medusae

121 were either used live or preserved in ethanol for later DNA processing.

\section{Molecular methods}

123 For the mitochondrial DNA assessment, genomic DNA was extracted using DNEasy Blood \&

124 Tissue kits (Qiagen) following the manufacturer's instructions. An approximately 600 base pair

125 part of the mitochondrial COI gene was amplified using universal primers (Folmer et al., 1994)

126 under the following conditions: $95^{\circ} 3$ minutes, 35 cycles of $95^{\circ}$ for 30 seconds, $48^{\circ}$ for 30

127 seconds, $72^{\circ}$ for 1 minute, and a final cycle of $72^{\circ}$ for 5 minutes. PCR products were visualized

128 on a $1.2 \%$ agarose gel stained with GelRed (Biotium) and purified using Qiaquick PCR

129 purification kits (Qiagen). Products were quantified with a Nanodrop 2000 spectrophotometer

130 (Nanodrop Technologies, Wilmington, Delaware, USA) and sequenced in both directions by

131 MWG Eurofins Operon. Chromatograms were assembled and DNA sequences were analyzed

132 using the Geneious v. 9 software platform (Kearse et al., 2012). Sequences were aligned using

133 ClustalW (Larkin et al., 2007). The alignment was verified by eye, and the ends were trimmed so

134 that all sequences were the same length. In order to facilitate direct comparisons with other 
135 published studies (e.g., Ortman et al., 2010; Zheng et al., 2014), mean Kimura 2-parameter

136 (K2P) distances between locations were calculated with MEGA 7 (Kumar, Stecher \& Tamura,

137 2016) and a neighbor-joining haplotype tree based on K2P distances was constructed using the

138 PAUP* 4 (Swofford, 2003) plugin in Geneious. We confirmed that the K2P haplotype tree was

139 consistent with a haplotype tree based on the best-fit model (GTR+I, as determined in ModelTest

140 using the Akaike Information Criterion in Geneious; Posada \& Crandall, 1998). DNA summary

141 statistics were calculated with DnaSP 5.10.01 (Librado \& Rozas, 2009).

\section{Results}

144 Samples were obtained from 8 NWA locations ranging from eastern Long Island Sound (near

145 Groton, Connecticut) in the south to Great Bay, New Hampshire in the north; 3 NWP locations

146 (Amur Bay and Vostok Bay in Peter the Great Gulf, Russia and Okirai Bay, Japan); one NEP

147 location (San Juan Island, Washington); and one NEA location (Iceland) (Table 1). Notably, the

148 NWP Amur Bay and Vostok Bay sites are notorious for harboring Gonionemus that cause severe

149 stings. While we did not quantitatively assess morphological differences of medusae between

150 regions, we report on some incidental observations. In general, the NWP and NWA samples

151 appeared relatively flat, ranged from dull orange to brown in color, and had relatively diminutive

152 gonads, although there was some variation in all of these traits (Fig. 1). An image of a NWA

153 Gonionemus medusa obtained from the Yale Peabody Museum originating from 1965 (pre-sting)

154 appeared similar (although has few tentacles) to contemporary NWA and NWP medusae (Fig.

155 1). In contrast, NEP medusae were distinctly more hemispherical, with bright orange fleshy $156 \operatorname{gonads}$ (Fig. 1). 

numbers KY437814-KY437985; Table 1). An additional 10 sequences already on Genbank from

159 the western Pacific were also analyzed (Table 1) so our final alignment contained 182 sequences.

160 Our trimmed alignment consisted of 501 base pairs. Overall, we found 7 haplotypes, with the

161 number of haplotypes in a given population ranging from 1 to 3 (Table 2). The mean between-

162 location Kimura 2-parameter (K2P) distances for all locations ranged from 0 to 0.076 (Table 3).

163 Pairwise distances between NWP and NWA locations ranged from $0.001-0.020$, while pairwise

164 distances between NWP/NWA and NEP/NEA locations ranged from 0.071-0.076. Haplotype

165 frequencies varied with geographic location (Table 2; Fig. 2; Fig. 3). Haplotype I was present

166 only in the Chinese specimens, and Haplotype II was present only in Okirai Bay, Japan, and

167 Haplotype III was present only in Vostok Bay. Haplotype IV was found in Vostok Bay and

168 Amur Bay, rare in Okirai Bay, and in varying frequencies in many NWA locations. In the NWA,

169 Haplotype IV was most abundant haplotype in the Pine Island, Mumford Cove, and

170 Sengekontacket Pond locations. It was present, but less abundant, in the Great Bay, Bass River,

171 Farm Pond and Potter Pond locations, and absent in Hamblin Pond. Haplotype V was found in

172 Great Bay and Bass River. Haplotype VI was found most commonly in Bass River, Farm Pond,

173 and Potter Pond, and exclusively in Hamblin Pond. All NEP (San Juan Island) and the single

174 NEA (Iceland) medusae shared an identical haplotype (Haplotype VII) that was not found in 175 either the NWA or NWP.

176 The two unique NWA haplotypes (Haplotypes V and VI) were separated from each other

177 by 12 nucleotide substitutions, and from the shared NWA/NWP (Haplotype IV) and unique

178 NWP haplotypes (Haplotypes I-III) by 7-8 nucleotide substitutions. The NWP haplotypes 
179 (Haplotypes I-IV), including the one shared with the NWA, differed from each other by 1-3

180 nucleotide substitutions.

181

182 Discussion

183 Population delineation and taxonomy

184 Our results refine, rather than resolve, the Gonionemus zoogeographic puzzle. Pairwise distances

185 between the NEP/NEA Gonionemus and the NWP/NWA Gonionemus are typical for

186 interspecific, rather than intraspecific, comparisons (Ortman et al., 2010; Zheng et al., 2014) and

187 thus suggest the possibility that the two groups may represent different species. Cnidarian

188 lineages differ substantially in their mitochondrial substitution rates (Shearer et al., 2002;

189 Govindarajan, Halanych \& Cunningham, 2005; Wares, 2014). And, based on a relative rate test

190 on COI in the closely related Maeotias marginata, Limnomedusae may exhibit relatively slow

191 rates (Shearer et al., 2002). Thus, the difference observed in NEP/NEA and NWP/NWA forms

192 could reflect especially deep divergences. It would be possible to calculate the substitution rate

193 between the NEP/NEA and NWP/NWA forms if their divergence date could be reasonably

194 estimated (e.g., from the opening of an Arctic passage, Wares \& Cunningham, 2001;

195 Govindarajan, Halanych \& Cunningham, 2005); however, there is too much uncertainty at this

196 point in the origin and dispersal history of Gonionemus as described below, to do this with

197 confidence.

198 Species-level genetic divergence is corroborated by our incidental morphological

199 observations, which are consistent with those from Russell (1953). A future taxonomic re-

200 assessment that incorporates morphology and multiple genetic markers could suggest that the

201 NWP/NWA form should be reclassified as G. murbachii Mayer 1901. Because G. murbachii was 
202 first described in the NWA, this line of reasoning would suggest that Gonionemus could actually

203 be native to the NWA. However, the situation is complex as our findings also refute previous

204 taxonomic thought and do not necessarily dismiss an invasion event. We also cannot rule out the

205 possibility that none of the contemporary NWA lineages correspond to G. murbachii. For clarity,

206 we will refer to the contemporary NWA/NWP form as "Gonionemus sp." for the remainder of

207 our discussion.

208 Naumov (1960) considered G. vertens and G. murbachii to be morphologically

209 distinguishable subspecies. He described the Pacific form (including both NWP and NEP forms)

210 as G. vertens vertens, and the Atlantic form as G. vertens murbachii. Naumov (1960) also noted

211 that only the G. vertens vertens form is toxic to humans (although only in some Russian

212 locations). Thus, while Naumov (1960) recognized two forms, as our results suggest, his

213 delineation of those two forms differs substantially from ours. Naumov (1960) assumed each

214 form was found in a different ocean, but our results show that both the vertens and Gonionemus

$215 \mathrm{sp}$. forms have disjunct distributions - with the vertens form in the NEP and NEA and the

216 Gonionemus sp. form in the NWP and NWA. This is suggestive of anthropogenic dispersal in

217 both forms. But again, the situation is complex, and possible explanations include both natural

218 and anthropogenic causes. We now evaluate 4 possible invasion history scenarios in light of

219 these results.

220 NWA invasion scenarios

221 Scenario 1 - "Traditional": In the "traditional" scenario (e.g., Tambs-Lyche, 1964; Edwards,

222 1976; Govindarajan \& Carman, 2016), the NEP/NEA and NWP/NWA forms are conspecific

223 (=G. vertens), G. vertens would therefore be widely distributed in the Northeast and Northwest

224 Pacific, where it may assume a range of morphological and toxicity phenotypes. Under this 
225 scenario, G. vertens was introduced multiple times from the Pacific to the NWA and NEA. NWA

226 populations would stem from an introduction in the late $19^{\text {th }}$ century of a less toxic variety (from

227 the NEP directly or by way of the NEA where it is also assumed introduced), and a second

228 introduction in the late $20^{\text {th }}$ century of the highly toxic NWP variety. The observed variation in

229 the different forms could be explained by environmental factors and not species differences - for

230 example, Miglietta \& Lessios (2009) showed that some hydrozoans can take on different

231 phenotypes in different locations and thus confound the reconstruction of invasion history.

232 However, our data strongly refute this scenario for Gonionemus, as the high pairwise distance

233 values between forms suggest that we are dealing with different species. Also, there are COI

234 haplotypes in the NWA that are not shared with the NEP or NWP and are quite divergent

235 themselves, and this could indicate a native NWA population (although this could also be due to

236 relatively limited sampling in the NWP and NEP). Lastly, we found no NEP/NEA haplotypes in

237 the NWA, despite extensive sampling near the locations of pre-1990 populations.

238 Scenario 2 - "Reverse invasion": In this scenario, we assume the NWA/NWP Gonionemus is

239 distinct from G. vertens in the NEP, and represents G. murbachii. The first record of the G.

240 murbachii form in the NWP is from the 1920s, over 2 decades after it was described in the NWA

241 (Yakovlev and Vaskovsky, 1993) Therefore, if we consider G. murbachii native to the NWA, its

242 subsequent observations in the NWP indicate that it may have been introduced from the NWA to

243 the NWP, in the opposite direction of what has been assumed. However, if the NWA form

244 invaded the NWP, we might expect there to be reduced diversity in the NWP, and that diversity

245 to be a subset of what is found in the NWA. But, although the resolving power of COI is limited,

246 this is not what we observed. Rather, COI haplotype diversity is similar in the NWA and NWP,

247 and there are unique haplotypes in both regions. Furthermore, NWP diversity is likely 
248 underestimated relative to the NWA, due to fewer sampling localities. And importantly, severe

249 stings were recorded several decades in the NWP before they were recorded in the NWA -

250 which, assuming the stings are heritable, strongly suggests an introduction in the direction of the

251 NWP to the NWA (and not vice versa). Lastly, this scenario assumes that, if the NWA/NWP

252 form is a different species than G. vertens, that it is G. murbachii, and not a third, undescribed,

253 species. Analysis of historical specimens may help to resolve this last issue.

254 Scenario 3 - "Lineage admixture": Here we also consider the NWA/NWP and NEP/NEA forms

255 to different species as in Scenario 2. The NWA and NWP forms are also different from each

256 other, although they represent different lineages of a single species (G. murbachii or

257 Gonionemus sp.) rather than different species. In this scenario we assume that the NWA contains

258 at least 2 ostensibly native cryptic lineages (possibly segregated geographically, southern and

259 northern New England; Fig. 3) that are distinct from each other and from the assumed native

260 NWP lineages. There are also multiple NWP lineages (and likely more than what we observed

261 with our limited sampling), only one of which is highly toxic (possibly represented by haplotype

262 IV, although mitochondrial haplotype should not be construed as equivalent to toxicity). The

263 NWA experienced a single invasion (likely in the late 1980s) of the toxic NWP lineage, which is

264 now interbreeding with the native NWA lineages. This hybridization may be facilitating NWA

265 blooms and regional range expansion.

266 While a naturally disjunct distribution for G. murbachii/sp. seems unlikely, it could be

267 explained by a trans-Arctic migration. Around $3 \frac{1}{2}$ million years ago, a well-documented sea

268 passage opened up connecting the north Pacific and the north Atlantic oceans (Vermeij 1991).

269 This passage enabled a large-scale migration of organisms, primarily in the direction of the

270 North Pacific to the North Atlantic. Migrating seaweeds and seagrasses would likely have carried 
271 associated fauna such as Gonionemus. More recent (e.g., in the Pleistocene; Palumbi \& Kessing,

272 1991) or earlier (e.g., Olsen et al., 2004) trans-Arctic migrations are also potentially possible.

273 The presence of unique haplotypes separated by several substitutions in both the NWA and NWP

274 suggests independently diverging populations consistent with this explanation. As described

275 above, the mitochondrial substitution rate might be particularly slow in Limnomedusae so that

276 differences represent deeper divergences consistent with an earlier migration. It is also possible

277 that multiple trans-Arctic migrations have occurred - for example, the first, resulting in the

278 NEP/NEA and NWP/NWA split, and a second, resulting in the different NWP and NWA

279 lineages.

280 An alternative variant of the "Lineage Admixture" scenario is that G. murbachii/sp. is

281 native to the NWP, where it went unnoticed until the $20^{\text {th }}$ century, and was introduced multiple

282 times into the NWA, beginning in the late $19^{\text {th }}$ century. This variant seems less likely, given the

283 number of steps between the two unique NWA haplotypes to each other and to the NWP

284 haplotypes. However additional sampling is necessary to definitively rule this out, and

285 importantly, this variant still involves lineage admixture which has evolutionary and ecological

286 implications as described below.

287 Scenario 4 - "Reverse admixture": The distribution of haplotype IV in the NWA appears to

288 contradict the Lineage Admixture hypothesis in that it is most abundant in the northern and

289 southern regions of the NWA range, and less abundant in the center, where the increase in NWA

290 toxicity was first noticed. The first severe stings in the NWA that we are aware of were reported

291 in 1990 in Waquoit Bay (which includes our Hamblin Pond site). But, we did not find the

292 Vladivostok-area haplotype IV at all in Hamblin Pond, and the frequency of haplotype IV is

293 greatest in the sites most distant from Hamblin Pond (Pine Island, Mumford Cove, Great Bay). It 
294 is possible that we did not find haplotype IV in Hamblin Pond because it was missed in our

295 sampling efforts or that haplotype IV has declined in frequency due to selection (again

296 remembering that mitochondrial haplotype is not equivalent to toxicity). It is also possible that

297 Gonionemus stings in other parts of the NWA are unreported and so that the current outbreak did

298 not begin in Waquoit Bay as the sting record in Govindarajan \& Carman (2016) might suggest.

299 However, we also consider a fourth scenario, where haplotype IV represents the historical NWA

300 Gonionemus populations. Here, the haplotype IV form is probably an invader from the NWP. It

301 is possible that despite an affinity with NWP toxic populations, painful stings did not occur

302 because toxicity was tempered by (unknown) environmental factors. The recent outbreak of

303 stings may indeed be caused by a new invasion, perhaps originating in the Waquoit Bay area, but

304 the source population is unknown.

305

Our COI results provide new insight into the history of Gonionemus in the NWA but

307 raise more questions than answers. Future studies should include sampling from several

308 additional North Pacific and North Atlantic locations and utilize additional genetic markers like

309 single nucleotide polymorphisms (SNPs) that can provide greater resolution than COI and

310 indicate whether hybridization has occurred. Additionally, a better understanding of the toxicity

311 phenotype and its relationship with environmental triggers and genotype is crucial, both for

312 understanding Gonionemus invasion history and for public health.

313 Gonionemus in all regions (NWP, NWP, NWA, NEA) may bloom episodically, and some

314 populations may wax and wane, conceivably over the course of decades, due to environmental

315 causes (Condon et al., 2013). Such periodicity could give the false impression of invasions. Both

316 scenarios 2 and 3 challenge the long-standing assumption that Gonionemus was introduced in the 
317 NWA. When Gonionemus was first recorded in the NWA, one of the locations was in Woods

318 Hole, MA, in a coastal pond adjacent to a marine laboratory (The Marine Biological Laboratory).

319 The jellyfish quickly became the focus of several scientific studies. The long history of faunal

320 studies in the Woods Hole region and the immediate attention that the jellyfish received after

321 they were first recorded seems to support Gonionemus's non-indigenous status in that region,

322 because it was assumed local scientists would have seen it earlier if it were present. However,

323 Gonionemus is capable of producing both asexual frustules and cysts, which can persist for

324 unknown lengths of time (Uchida, 1976). In some species, cysts can potentially persist over

325 decades (Bouillon et al., 2004). More study is required to understand how long these asexual

326 stages can persist, the environmental triggers for their germination, and if they have played a role

327 in NWA Gonionemus population dynamics.

328 Evolutionary processes influencing NWA Gonionemus

329 Multiple evolutionary processes can influence colonizing populations, including

330 introduced populations. It is often assumed that colonizing populations harbor only a subset of

331 the genetic diversity found in parent populations. As genetic diversity is thought to promote

332 population persistence, it follows that the low diversity in founding populations would make it

333 difficult for them to become established. The fact that many colonizing populations do become

334 established despite their assumed low diversity is called the "genetic paradox". Multiple inputs

335 followed by lineage admixture may be a mechanism to overcome the "genetic paradox" (Kolbe

336 et al., 2004; Dlugosch \& Parker, 2008). In some cases, incoming populations may come from

337 different source areas, and subsequent interbreeding could generate novel genetic combinations

338 that also may help the nascent population become established (Kolbe et al., 2004). 
340 evolutionary change in NWA Gonionemus populations. This process could be occurring either

341 between multiple anthropogenic inoculation events (e.g., Scenario 1) or between long-diverged

342 intraspecific lineages (e.g., Scenarios 3 and 4). The resulting genetic changes could be promoting

343 the prominent blooms and apparent rapid range expansion that has been observed since the

344 1990s. After the 1930s eelgrass dieoff, NWA Gonionemus was known primarily from a single

345 pond on the island of Martha's Vineyard, Massachusetts, and very occasional reports from the

346 Gulf of Maine (Govindarajan \& Carman, 2016). These populations, which were apparently

347 marginal for decades, may have been re-invigorated when mixed with recent NWP individuals,

348 which provided the genetic material to enhance the jellyfish's fitness. Because our dataset is

349 limited to a single mitochondrial marker, we cannot evaluate here if introgression or 350 hybridization has occurred.

351 In contrast to the genetic paradox paradigm, the assumption that genetic diversity is low

352 in colonizing populations may not hold true for many invading populations (e.g., Darling et al.,

353 2008), and may be sufficient to allow for adaptive changes driven by natural selection

354 (Koskinen, Haugen \& Primmer, 2002; Wares, Hughes \& Grosberg, 2005). Adaptive evolution

355 could be responsible for differences in phenotype between invading and source populations in

356 some species. Similarly, it is possible that contemporary NWA populations may be experiencing

357 rapid adaptive evolution. However, detection of adaptation can be obscured by phenotypic

358 plasticity (Tepolt, 2015; Krueger-Hadfield, 2016). Thus, future studies that use nuclear markers

359 capable of finer-scale resolution and detection of hybridization, coupled with phenotypic

360 characterization in Pacific and NWA regions, are necessary to assess both the lineage admixture

361 and adaptive evolution hypotheses in Gonionemus. 
363 The toxicity phenotype

364 The toxicity phenotype stands out with special importance due to the concerns about

365 envenomations, and it may also play a role in the NWA range expansion. Gonionemus medusae

366 are predators that consume a variety of zooplankton prey (Arai \& Brinckmann-Voss, 1980), and

367 so increased toxicity could improve prey capture or deter predators and lead to population

368 growth. The current NWA toxicity phenotype appears more aggressive than in pre-1990

369 populations, as evidenced by the history of stings to humans (Govindarajan \& Carman, 2016).

370 This observation could be due to lineage admixture between contemporary and historical NWA

371 populations, recent adaptation in contemporary NWA populations, and/or plasticity due to

372 environmental conditions.

373 The contemporary NWA toxicity phenotype could be subtly different than the NWP

374 toxicity phenotype. In the NWP, especially off of Vladivostok, Gonionemus stings are a well-

375 known hazard and there have periodically been mass-stinging events. In an extreme example, on

376 just one day in June, 1966, over 1000 people were stung by Gonionemus off of the Amur Bay

377 recreational area (Mikulich \& Naumov, 1974). Stings seem to be more common in the

378 Vladivostok region in hot, dry years, suggesting environmental factors play a role. Also, cold

379 winters associated with ice cover may be unfavorable for Gonionemus as a result of scour on the

380 eelgrass beds and the pulse of fresh water when the ice melts (Mikulich \& Naumov, 1974).

381 Govindarajan and Carman (2016) described a number of Gonionemus sting symptoms

382 reported by victims including severe pain, respiratory difficulty, and temporary paralysis. It

383 should be noted that these symptoms were based on the victims' personal accounts of the stings

384 and not medical reports. Russian accounts describe additional symptoms including blindness and 
385 hallucinations (Michaleff, 1974; Yatskov, 1974) that have not been reported in the NWA as far

386 as we are aware. However, because sting symptoms may be described differently by individuals,

387 and individuals likely vary in their physiological sting responses, a toxicity assay that is

388 objective and quantitative is necessary to accurately compare jellyfish toxicities. Given the

389 apparent increase in Gonionemus bloom frequency and NWA range expansion, this is an area

390 where more research is urgently needed.

391

392

The biogeography of Gonionemus has perplexed scientists for decades. New sightings in

393 the NWA and recent reports of extremely painful stings speak to an urgent need for a better

394 understanding of its origins, which can come from an approach that integrates its taxonomy,

395 genetics, life cycle dynamics, and historical records (e.g., Pringle et al., 2009). While our study

396 resolves some questions, it leads to many more new ones. We found that NEP G. vertens is

397 distinct from the form found in the NWA and NWP. Gonionemus in the NWA and NWP may be

398 G. murbachii, although a comprehensive taxonomic assessment is required to confirm the

399 classification of this form. Our results show that both the NWA and NWP contain independent

400 Gonionemus lineages, possibly as a result of trans-Arctic migrations. We also resurrect the

401 hypothesis that Gonionemus could be native to the NWA, in contrast with the long held

402 assumption that it was introduced by anthropogenic means. One lineage, which we term

403 haplotype IV, is shared with the well - known highly toxic populations in the coastal

404 Vladivostok-area in the Sea of Japan. However, because the distribution of haplotype IV does

405 not correspond with the geographic distribution of NWA sting reports and mitochondrial lineage

406 is not equivalent to toxicity, we cannot assume that this form that was introduced recently. While 
407 it seems less likely, it is also possible that an invasion occurred in the reverse direction - from

408 the NWA to the NWP. More research is needed to resolve these competing scenarios.

409

410 Acknowledgements

411 We thank Bill Grossman and Dave Remsen (Marine Biological Laboratory), Dave Grunden

412 (Shellfish Department, Town of Oak Bluffs, Massachusetts), Fred Short (University of New

413 Hampshire), Charlie Woods (University of Connecticut), Claudia Mills (University of

414 Washington), Alexei V. Chernyshev (A.V. Zhirmunsky Institute of Marine Biology, National

415 Scientific Center of Marine Biology) and Hiroshi Miyake (Kitasato University) for assistance in

416 collecting jellyfish and providing samples. We thank Óskar Sindri Gíslason (Southwest Iceland

417 Nature Research Centre) for collecting the Icelandic specimen and Allen Collins (Smithsonian

418 Institution) for obtaining its COI sequence. We thank Lubov Petrova (Primorsky Aquarium) and

419 Eric Lazo-Wasem (Yale Peabody Museum) for supplying Gonionemus photographs. We thank

420 Ferdinando Boero and Cinzia Gravili (Università del Salento) for sharing their literature

421 collection.

422 References

423 Agassiz L .1862. Contributions to the Natural History of the United States of America. Vol. 4, 424 Little, Brown and Company, Boston, 330 pp.

425 Arai MN, Brinckmann-Voss A. 1980. Hydromedusae of British Columbia and Puget Sound.

426 Canadian Journal of Fisheries and Aquatic Sciences 204:1-192.

427 Bakker C. 1980. On the distribution of 'Gonionemus vertens' A. Agassiz (Hydrozoa,

428 Limnomedusae), a new species in the eelgrass beds of Lake Grevelingen (S.W.

429 Netherlands). Hydrobioligal Bulletin 14(3):186-195. 
430 Bouillon J, Medel MD, Pagès F, Gili JM, Boero F, Gravili, C. 2004. Fauna of the Mediterranean $431 \quad$ Hydrozoa. Scientia Marina 68(S2):5-438.

432 Carlton JT. 1996. Biological invasions and cryptogenic species. Ecology 77(6):1653-1655.

433 Carlton JT. 2009. Deep invasion ecology and the assembly of communities in historical time. In 434 Biological invasions in marine ecosystems (pp. 13-56). Springer Berlin Heidelberg.

435 Condon RH, Duarte CM, Pitt KA, Robinson, KL, Lucas CH, Sutherland KR, Mianzan HW, 436 Bogeberg M, Purcell JE, Decker MB, Uye SI. 2013. Recurrent jellyfish blooms are a consequence of global oscillations. Proceedings of the National Academy of Sciences

Darling JA, Bagley MJ, Roman JO, Tepolt CK, Geller JB. 2008. Genetic patterns across multiple introductions of the globally invasive crab genus Carcinus. Molecular Ecology 17(23):4992-5007.

442 110(3):1000-1005

Dlugosch KM, Parker IM. 2008. Invading populations of an ornamental shrub show rapid life history evolution despite genetic bottlenecks. Ecology Letters 11(7):701-9.

Edwards C. 1976. A study in erratic distribution: the occurrence of the medusa Gonionemus in relation to the distribution of oysters. Advances in Marine Biology 14:251-284.

Folmer O, Black M, Hoeh W, Lutz R, Vrijenhoek R. 1994. DNA primers for amplification of mitochondrial cytochrome c oxidase subunit I from diverse metazoan invertebrates. Molecular marine biology and biotechnology 3(5):294-299.

Gallardo B, Clavero M, Sánchez MI, Vilà M. 2016. Global ecological impacts of invasive species in aquatic ecosystems. Global change biology 22(1):151-163.

Geller JB, Darling JA, Carlton, JT. 2010. Genetic perspectives on marine biological invasions. Annual Review of Marine Science 2:367-393. 
453 Geller JB, Walton ED, Grosholz ED, Ruiz GM. 1997. Cryptic invasions of the crab Carcinus 454 detected by molecular phylogeography. Molecular Ecology 6(10):901-6.

455 Govindarajan AF, Halanych KM, Cunningham, CW. 2005. Mitochondrial evolution and 456 phylogeography in the hydrozoan Obelia geniculata (Cnidaria). Marine Biology

Govindarajan AF, Carman MR. 2016. Possible cryptic invasion of the Western Pacific toxic population of the hydromedusa Gonionemus vertens (Cnidaria: Hydrozoa) in the Northwestern Atlantic Ocean. Biological Invasions 18(2):463-9.

461

462

463

464

465

466

467

468

469

470

471

472

473 146(2):213-222.

Kolbe JJ, Glor RE, Schettino LR, Lara AC, Larson A, Losos JB. 2004. Genetic variation increases during biological invasion by a Cuban lizard. Nature 431(7005):177-81.

Kearse M, Moir R, Wilson A, Stones-Havas S, Cheung M, Sturrock S, Buxton S, Cooper A, Markowitz S, Duran C, Thierer T. 2012. Geneious Basic: an integrated and extendable desktop software platform for the organization and analysis of sequence data. Bioinformatics 28(12):1647-9.

Koskinen MT, Haugen TO, Primmer CR. 2002. Contemporary fisherian life-history evolution in small salmonid populations. Nature 419(6909):826-30.

Krueger-Hadfield SA, Kollars NM, Byers JE, Greig TW, Hammann M, Murray DC, Murren CJ, Strand AE, Terada R, Weinberger F, Sotka EE. 2016. Invasion of novel habitats uncouples haplo-diplontic life cycles. Molecular Ecology 25:3801-3816.

Kumar S, Stecher G, Tamura K. 2016. MEGA7: Molecular Evolutionary Genetics Analysis version 7.0 for bigger datasets. Molecular Biology and Evolution 33(7):1870-4. 
474 Larkin MA, Blackshields G, Brown NP, Chenna R, McGettigan PA, McWilliam H, Valentin F, 475 Wallace IM, Wilm A, Lopez R+3 more. 2007. Clustal W and Clustal X version 2.0. $476 \quad$ Bioinformatics 23:2947-2948.

477 Librado P, Rozas J. 2009. DnaSP v5: A software for comprehensive analysis of DNA 478 polymorphism data. Bioinformatics 25:1451-1452.

479 Miglietta MP, Lessios HA. 2009. A silent invasion. Biological Invasions 11(4):825-834.

480 Michaleff PV. 1974. On serious cases of toxicosis caused by medusa Gonionemus vertens

481

482

483

484

485

486 vertens affection and proceeding in deep dullness. Research of the venomous medusa Gonionemus vertens vertens. Far East Scientific Center of the Academy of Sciences of the USSR, 53-58.

Mikulich LV Naumov DV. 1974. Venomous medusa Gonionemus vertens, its taxonomy, morphology, life cycle, biology and distribution. Research of the venomous medusa Gonionemus vertens vertens. Far East Scientific Center of the Academy of Sciences of the USSR, 9-22.

Molnar JL, Gamboa RL, Revenga C, Spalding MD. 2008. Assessing the global threat of invasive species to marine biodiversity. Frontiers in Ecology and the Environment 6(9):485-92.

Naumov DV. 1960. Hydroids and hydromedusae of the USSR. Keys to the Fauna of the USSR, Zoological Institute of the Academy of Sciences of the USSR, 70. Translated from Russian by the Israel Program for Scientific Translations.

Olsen JL, Stam WT, Coyer JA, Reusch TB, Billingham M, Boström C, Calvert E, Christie H, Granger S, Lumiere RL, Milchakova N. North Atlantic phylogeography and large-scale population differentiation of the seagrass Zostera marina L. Molecular ecology 13(7):1923-41. 
497 Ortman BD, Bucklin A, Pagès F, Youngbluth M. 2010. DNA Barcoding the Medusozoa using 498 mtCOI. Deep Sea Research Part II: Topical Studies in Oceanography 57(24):2148-2156

499 Palumbi SR, Kessing BD. 1991. Population biology of the trans-Arctic exchange: mtDNA

500 sequence similarity between Pacific and Atlantic sea urchins. Evolution 45(8):1790-805.

501 Perkins HF. 1903. The development of Gonionema Murbachiii. Proceedings of the Academy of $502 \quad$ Natural Sciences Philadelphia 54:750-790.

503 Pigulevsky SV, Michaleff PV. 1969. Poisoning by the medusa Gonionemus vertens in the Sea of 504 Japan. Toxicon 7(2):145-149.

505 Posada D, Crandall KA. 1998. Modeltest: testing the model of DNA substitution. Bioinformatics 506 14(9):817-8.

507

508

509

510

511

512

513

514

515

516

517

518

519

Pringle A, Adams RI, Cross HB, Bruns TD. 2009. The ectomycorrhizal fungus Amanita phalloides was introduced and is expanding its range on the west coast of North America. Molecular Ecology 18(5):817-33.

Pyšek P, Richardson DM. 2010. Invasive species, environmental change and management, and health. Annual Review of Environment and Resources 35:25-55.

Rodriguez CS, Pujol MG, Mianzan HW, Genzano GN. 2014. First record of the invasive stinging medusa Gonionemus vertens in the southern hemisphere (Mar del Plata, Argentina). Latin American Journal of Aquatic Research 42(3):653-657.

Roman J. 2006. Diluting the founder effect: cryptic invasions expand a marine invader's range. Proceedings of the Royal Society of London B: Biological Sciences 273(1600):2453-9.

Ruiz GM, Fofonoff PW, Carlton JT, Wonham MJ, Hines AH. 2000. Invasion of coastal marine communities in North America: apparent patterns, processes, and biases. Annual Review of Ecology and Systematics. 31:481-531. 
520 Russell FS. 1953. The medusae of the British Isles: anthomedusae, leptomedusae,

521 limnomedusae, trachymedusae and narcomedusae. University Press; Pp. 398-403.

522 Shearer TL, Van Oppen MJ, Romano SL, Wörheide G. 2002. Slow mitochondrial DNA

523 sequence evolution in the Anthozoa (Cnidaria). Molecular Ecology 11(12):2475-87.

524 Simon-Bouhet B, Garcia-Meunier P, Viard F. 2006. Multiple introductions promote range

525 expansion of the mollusc Cyclope neritea (Nassariidae) in France: evidence from mitochondrial sequence data. Molecular Ecology 15(6):1699-711.

Swofford DL. 2003. PAUP*. Phylogenetic Analysis Using Parsimony (*and Other Methods). Version 4. Sinauer Associates, Sunderland, Massachusetts.

Tambs-Lyche H. 1964. Gonionemus vertens L. Agassiz (Limnomedusae) - a zoogeographical puzzle. Sarsia 15:1-8

Tepolt CK. 2015. Adaptation in marine invasion: a genetic perspective. Biological Invasions 17(3):887-903.

Uchida T. 1976. A new sporozoan-like reproduction in the hydromedusa, Gonionemus vertens. Proc Japan Acad 52(71):387-388.

Vermeij GJ. 1991. Anatomy of an invasion: the trans-Arctic interchange. Paleobiology 17:281-

Wares JP. 2014. Mitochondrial cytochrome b sequence data are not an improvement for species identification in Scleractinian corals. PeerJ 2:e564.

Wares JP, Cunningham CW. 2001. Phylogeography and historical ecology of the North Atlantic intertidal. Evolution 55(12):2455-69.

541 Wares JP, Hughes AR, Grosberg RK. 2005. Mechanisms that drive evolutionary change: insights from species introductions and invasions. In: Sax D, Stachowicz JJ, Gaines S, eds. 
543 Species invasions: insights into ecology, evolution, and biogeography, Sinauer

$544 \quad$ Associates, 229-257.

545 Yakovlev YM, Vaskovsky VE. 1993. The toxic krestovik medusa Gonionemus vertens. Russian $546 \quad$ J Mar Biol 19(5-6):287-294.

547 Yatskov LP. 1974. Neurological characteristics of the diseases caused by venomous medusa $548 \quad$ Gonionemus vertens vertens. Research of the venomous medusa Gonionemus vertens 549 vertens. Far East Scientific Center of the Academy of Sciences of the USSR, 46-52.

550 Yund PO, Collins C, Johnson SL. 2015. Evidence of a native northwest Atlantic COI haplotype 551 clade in the cryptogenic colonial ascidian Botryllus schlosseri. The Biological Bulletin $552 \quad 228(3): 201-216$.

553 Zheng L, He J, Lin Y, Cao W, Zhang W. 2014. 16S rRNA is a better choice than COI for DNA 554 barcoding hydrozoans in the coastal waters of China. Acta Oceanologica Sinica 33(4):

555 $55-76$. 


\section{Table 1 (on next page)}

Sampling locations and location abbreviations. 


\begin{tabular}{|c|c|c|c|c|c|}
\hline Region & Site & Abbreviation & Latitude & Longitude & Reference \\
\hline \multirow[t]{8}{*}{ NWA } & Great Bay, NH & GB & 43.070 & -70.900 & This study \\
\hline & $\begin{array}{l}\text { Bass River, } \\
\text { Yarmouth, MA }\end{array}$ & $\mathrm{BR}$ & 41.707 & -70.186 & This study \\
\hline & $\begin{array}{l}\text { Hamblin Pond, } \\
\text { Mashpee, MA }\end{array}$ & $\mathrm{HP}$ & 41.573 & -70.508 & This study \\
\hline & $\begin{array}{l}\text { Farm Pond, Oak } \\
\text { Bluffs, MA }\end{array}$ & FP & 41.447 & -70.557 & This study \\
\hline & $\begin{array}{l}\text { Sengekontacket } \\
\text { Pond, } \\
\text { Edgartown, MA }\end{array}$ & SG & 41.416 & -70.569 & This study \\
\hline & $\begin{array}{l}\text { Potter Pond, } \\
\text { North Kingston, } \\
\text { RI }\end{array}$ & PP & 41.382 & -71.531 & This study \\
\hline & $\begin{array}{l}\text { Mumford Cove, } \\
\text { Groton, CT }\end{array}$ & $\mathrm{MC}$ & 41.324 & -72.019 & This study \\
\hline & $\begin{array}{l}\text { Pine Island, } \\
\text { Groton, CT }\end{array}$ & PI & 41.314 & -72.058 & This study \\
\hline \multirow[t]{4}{*}{ NWP } & $\begin{array}{l}\text { Amur Bay (Peter } \\
\text { the Great Gulf) }\end{array}$ & $\mathrm{AB}$ & 43.199 & 131.919 & This study \\
\hline & $\begin{array}{l}\text { Vostok Bay } \\
\text { (Peter the Great } \\
\text { Gulf) }\end{array}$ & VB & 42.892 & 132.729 & This study \\
\hline & $\begin{array}{l}\text { Okirai Bay, } \\
\text { Japan (Pacific) }\end{array}$ & JP & 39.092 & 141.833 & This study \\
\hline & China & $\mathrm{CH}$ & $\mathrm{N} / \mathrm{A}$ & $\mathrm{N} / \mathrm{A}$ & $\begin{array}{l}\text { He et al., } \\
\text { unpublished; } \\
\text { KF926139 }\end{array}$ \\
\hline NEP & $\begin{array}{l}\text { San Juan Island, } \\
\text { WA }\end{array}$ & FH & 48.535 & -123.008 & This study \\
\hline NEA & Álftanes, Iceland & IC & 64.098 & -22.033 & This study \\
\hline
\end{tabular}




\section{Table 2 (on next page)}

Summary statistics for NWA and NWP samples. $\mathrm{N}=$ number of samples; $\mathrm{H}=$ number of haplotypes; $\mathrm{Hd}=$ haplotype diversity; $\mathrm{Pi}=$ nucleotide diversity. Site abbreviations are provided in Table 1. 


\begin{tabular}{|c|c|c|c|c|c|c|}
\hline Region & Site & $\mathbf{N}$ & $\mathbf{H}$ & $\begin{array}{l}\text { Haplotype } \\
\text { counts }\end{array}$ & Hd & $\mathbf{P i}$ \\
\hline \multirow[t]{8}{*}{ NWA } & GB & 7 & 2 & $\begin{array}{l}\text { Hap IV - } 3 \\
\text { Hap V - } 4\end{array}$ & 0.571 & 0.00912 \\
\hline & $\mathrm{BR}$ & 17 & 3 & $\begin{array}{l}\text { Hap IV - } 2 \\
\text { Hap V - } 3 \\
\text { Hap VI - } 12\end{array}$ & 0.485 & 0.01004 \\
\hline & HP & 18 & 1 & Hap VI - 18 & 0 & 0 \\
\hline & $\mathrm{SG}$ & 3 & 2 & $\begin{array}{l}\text { Hap IV - } 2 \\
\text { Hap VI - } 1\end{array}$ & 0.667 & 0.00931 \\
\hline & FP & 17 & 2 & $\begin{array}{l}\text { Hap IV - } 1 \\
\text { Hap VI - } 16\end{array}$ & 0.0118 & 0.00164 \\
\hline & $\mathrm{PP}$ & 22 & 2 & $\begin{array}{l}\text { Hap IV- } 2 \\
\text { Hap VI - } 20\end{array}$ & 0.173 & 0.00242 \\
\hline & $\mathrm{MC}$ & 14 & 2 & $\begin{array}{l}\text { Hap IV - } 13 \\
\text { Hap VI - } 1\end{array}$ & 0.143 & 0.00200 \\
\hline & PI & 24 & 2 & $\begin{array}{l}\text { Hap IV - } 23 \\
\text { Hap VI - } 1\end{array}$ & 0.083 & 0.00116 \\
\hline \multirow[t]{4}{*}{ NWP } & $\mathrm{AB}$ & 3 & 1 & Hap IV - 3 & 0 & 0 \\
\hline & VB & 30 & 2 & $\begin{array}{l}\text { Hap III - } 4 \\
\text { Hap IV - } 26\end{array}$ & 0.239 & 0.00048 \\
\hline & JP & 12 & 2 & $\begin{array}{l}\text { Hap II - } 11 \\
\text { Hap IV - } 1\end{array}$ & 0.167 & 0.001 \\
\hline & $\mathrm{CH}$ & 10 & 1 & Hap I - 10 & 0 & 0 \\
\hline NEP & FH & 4 & 1 & Hap VII - 4 & 0 & 0 \\
\hline NEA & IC & 1 & 1 & Hap VII - 1 & 0 & 0 \\
\hline
\end{tabular}




\section{Table 3 (on next page)}

Mean between-location Kimura 2-parameter distances. Site abbreviations are listed in Table 1. 


\begin{tabular}{|l|l|l|l|l|l|l|l|l|l|l|l|l|l|}
\hline & GB & BR & HP & SG & FP & PP & MC & PI & AB & VB & JP & CH & FH \\
\hline BR & .017 & & & & & & & & & & & & \\
\hline HP & .021 & .006 & & & & & & & & & & & \\
\hline SG & .013 & .011 & .009 & & & & & & & & & & \\
\hline FP & .021 & .007 & .001 & .009 & & & & & & & & & \\
\hline PP & .020 & .007 & .001 & .009 & .002 & & & & & & & & \\
\hline MC & .010 & .012 & .013 & .005 & .012 & .012 & & & & & & & \\
\hline PI & .010 & .013 & .014 & .005 & .013 & .012 & .002 & & & & & & \\
\hline AB & .009 & .013 & .014 & .005 & .013 & .013 & .001 & .001 & & & & & \\
\hline VB & .010 & .013 & .014 & .005 & .014 & .013 & .001 & .001 & 0 & & & & \\
\hline JP & .013 & .015 & .016 & .009 & .015 & .015 & .006 & .006 & .006 & .006 & & & \\
\hline CH & .013 & .015 & .016 & .009 & .016 & .015 & .007 & .006 & .006 & .006 & .004 & & \\
\hline FH & .076 & .074 & .074 & .072 & .074 & .074 & .072 & .072 & .072 & .071 & .074 & .069 & \\
\hline IC & .076 & .074 & .074 & .072 & .074 & .074 & .072 & .072 & .072 & .071 & .074 & .069 & 0 \\
\hline
\end{tabular}




\section{Figure 1}

Comparison of Gonionemus medusae.

In general, most of the NWA and NWP medusae observed in this study were relatively flat and have thin, dull brown and orange gonads, and the 4 NEP medusae used in this study were relatively hemispherical and had bright orange fleshy gonads. Gonads are found on the radial canals. Note, photos were taken under different lighting conditions so the colors are not directly comparable. While scale bars are not shown, the maximum size of mature medusae that we recorded was $2.5 \mathrm{~cm}$ in the NWA and $3.0 \mathrm{~cm}$ in the NWP. A) Typical contemporary NWA Gonionemus. Photo credit A. Govindarajan. B) Less commonly observed contemporary NWA Gonionemus with fleshier gonads. Note the tentacles are contracted. Photo credit A. Govindarajan. C) NWP (Vladivostok-area) Gonionemus with an eelgrass blade. Photo credit L. Petrova. D) NWP (Vladivostok-area) Gonionemus in flow conditions. Photo credit L. Petrova. E) 1960s NWA Gonionemus from the Woods Hole region. Some tentacles are missing but note the relatively thin gonads. Photo credit William Amos, Marine Biological Laboratory, courtesy of the Peabody Museum of Natural History, Yale University. F) Contemporary Gonionemus from the NEP (San Juan Island). Photo credit A. Govindarajan. 

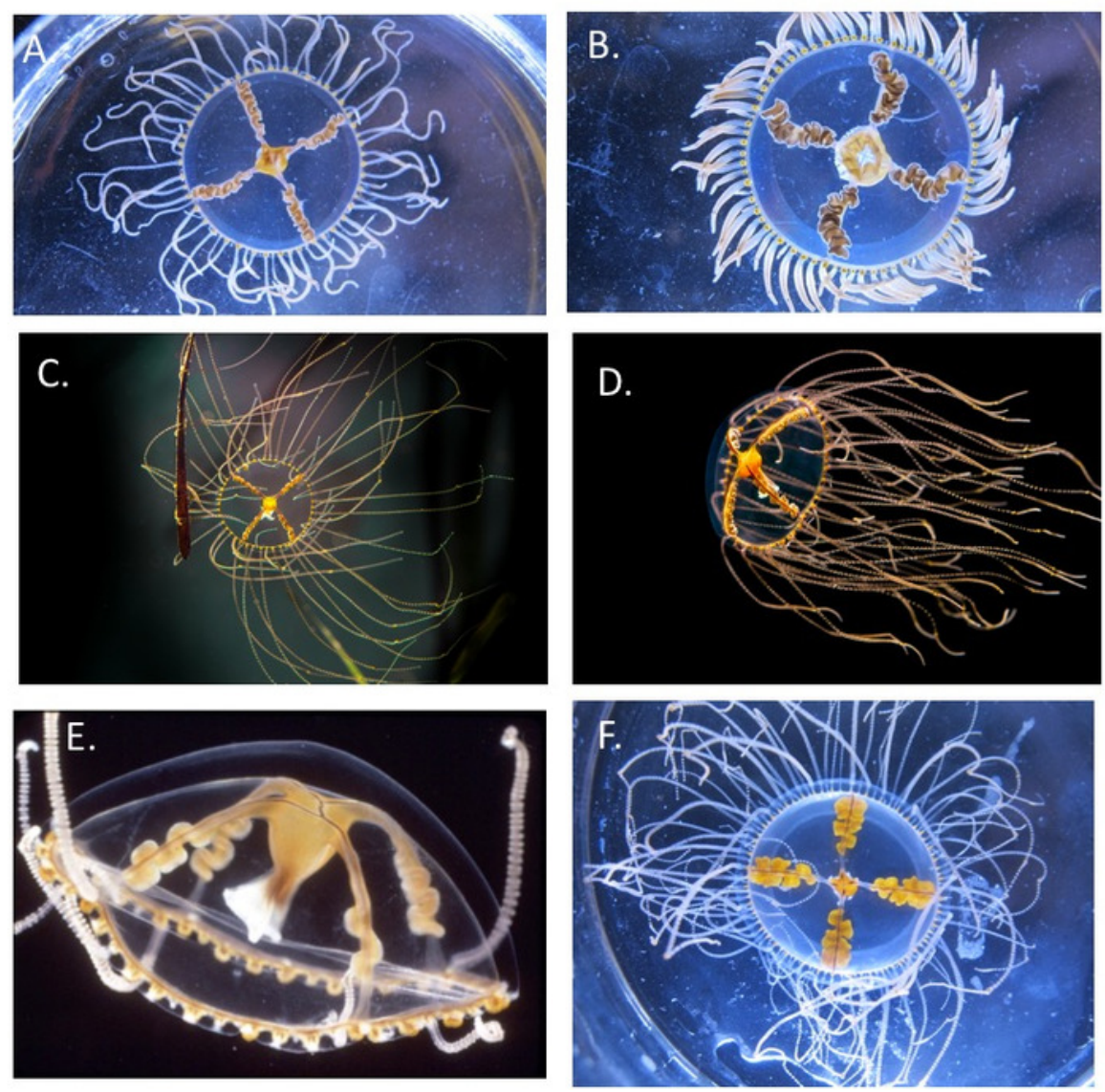
Figure 2 (on next page)

Neighbor-joining tree of COI haplotypes based on Kimura 2-parameter distances.

The regions where the haplotypes are found are indicated. 


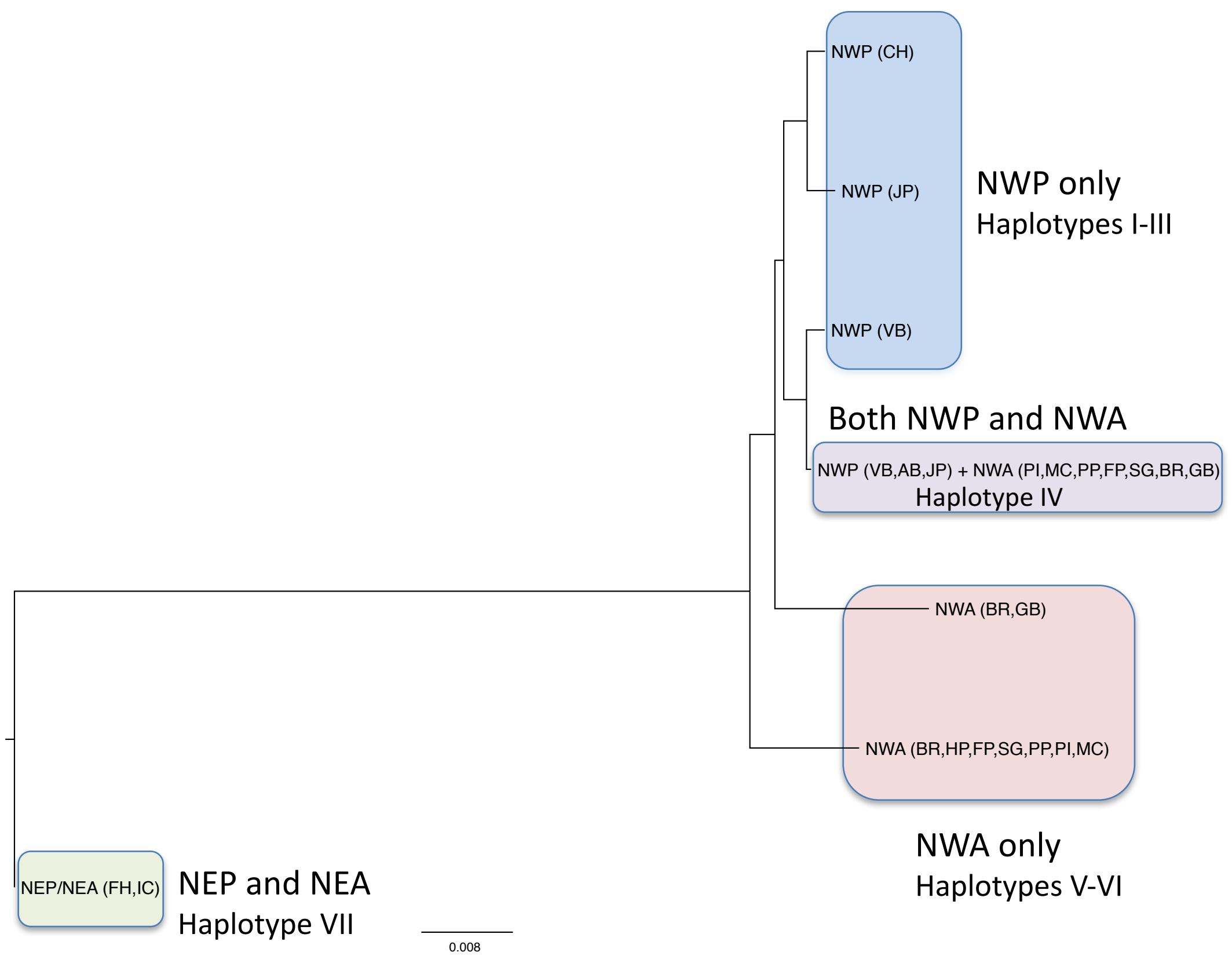


Figure 3 (on next page)

Geographic distribution of haplotypes.

A) Distributions in the Northwest Atlantic; and B) Distributions in the Northwest Pacific. Closely spaced sites are combined (Pine Island and Mumford Cove; Farm Pond and Sengekontacket Pond; Amur Bay and Vostok Bay). Individual site haplotype data are presented for these sites in Table 2 and Figure 2. The $\mathrm{CH}$ haplotype presumably originates from the Chinese coast in the NWP but the location is not provided (unpublished Genbank entry) and so it is not depicted here. Site abbreviations are listed in Table 1 and haplotype numbers are as in Fig. 2. 

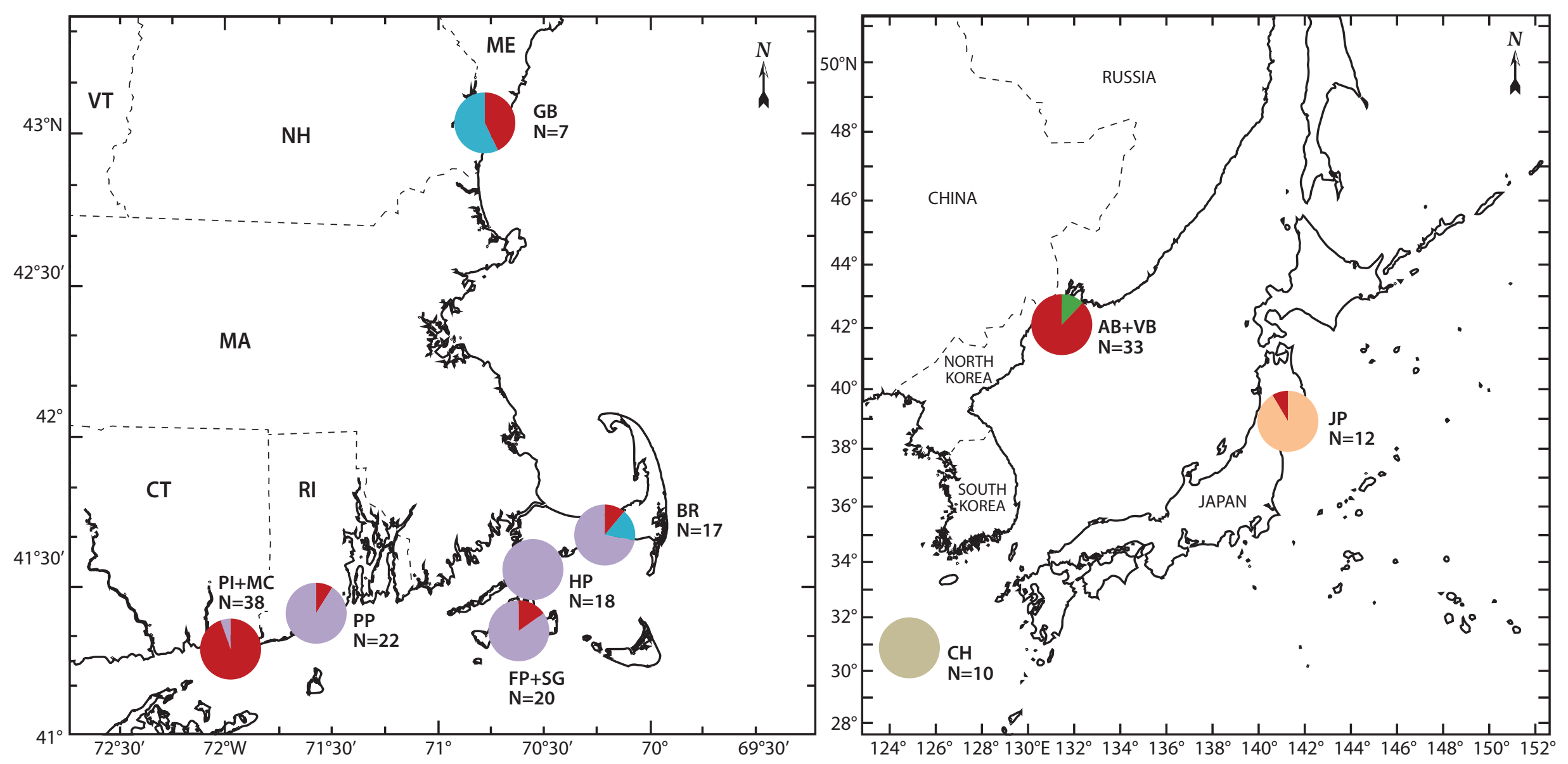

$\square$ HAPI $\square$ HAP $\|$ HAP III $\square$ HAPIV $\square$ HAPV $\square$ HAPVI 